\title{
Experimental Investigation on Mechanical Properties of A/GFRP, B/GFRP and AB/GFRP Polymer Composites
}

\author{
VELMURUGAN NATARAJAN ${ }^{*}$, RAVI SAMRAJ ${ }^{2}$, JAYABALAKRISHNAN DURAIVELU ${ }^{3}$, \\ PRABHU PAULRAJ ${ }^{3}$ \\ ${ }^{1}$ Research Scholar, Department of Mechanical Engineering, Anna University, Chennai Tamil Nadu 600028, India \\ ${ }^{2}$ Department of Mechanical Engineering, Chennai Institute of Technology, Chennai, Tamil Nadu 600069, India \\ ${ }^{3}$ Department of Mechanical Engineering, Sriram Engineering College, Chennai, Tamil Nadu 602024, India
}

\begin{abstract}
This study aims to reveal the consequence of thickness reinforcement on Fiber Laminates (Polyester Resin, Glass Fiber, Aluminum, and Bentonite) and to see if it can enhance the mechanical properties and resistance of laminates. Glass fiber reinforced polymer composites have recently been used in automotive, aerospace, and structural applications where they will be safe for the application's unique shape. Hand layup was used to fabricate three different combinations, including Aluminium /Glass fiber reinforced polyester composites (A/GFRP), Bentonite/Glass fiber reinforced polyester composites (B/GFRP), and Aluminium\&Bentonie/Glass fiber reinforced polyester composites (AB/GFRP). Results revealed that AB/GFRP had better tensile strength, flexural strength, and hardness than GFRP and A/GFRP. Under normal atmospheric conditions and after exposure to boiling water, hybrid Aluminium\&Bentonite and glass fiber-reinforced nanocomposites have improved mechanical properties than other hybrid composites. After exposure to temperature, the flexural strength, tensile strength and stiffness of AB/GFRP Composites are $40 \%$ higher than A/GFRP and $17.44 \%$ higher than B/GFRP Composites.
\end{abstract}

Keywords: Composite, Bentonite, Aluminium power, Glass fiber

\section{Introduction}

Glass fiber-reinforced plastic (GFRP) materials are non-conductive, making them ideal for high voltage applications such as insulators and power transmission pylons [1]. Typically, fillers are used to strengthen polymer materials to increase their mechanical characteristics. Such materials like nano clay can be widely used in diverse areas including electronics, communication, transportation, construction and consumer products due to their enhanced mechanical properties. Glass fibers, clay, silica and carbon fibers are popular fillers. According to the theories of Cox and Kelly [2,3], the degree to which the filler is reinforced is determined by its stiffness and aspect ratio, as well as the adhesive strength between the filler and the polymer matrix. Polymer clay nanocomposites have garnered great attention when it was discovered that by adding nano-sized clay particles, the polymer characteristics may be significantly enhanced $[4,5]$. The inclusion of nano clay particles greatly improves the characteristics of thermoset unsaturated polyester [6]. The function of acrylonitrile-butadiene rubber (ABR) and nano-silica in epoxy composites with stitched E-glass fiber, with a novel approach of layering rubber sheet, resulted in improving the reinforcing effect in FRP and also confirmed that the accumulation of nano-silica enhanced the Mechanical properties of the composites. Rubber-based Epoxy composites with improved penetrations find major applications in automobile body panels, armor-based panels and also in domestic manufacturing applications $[7,8]$. An epoxy biocomposite was prepared using rice husk-derived ultrafine biosilica that possesses high-performance coating application in aircraft passenger air-duct application for heat reduction and to enhance the air's quality [9]. The epoxy resin hybrid composite finds applications in automobiles and aircraft was prepared by adding silicon coupling grafted ferric oxide and E-glass fiber and characterized for tensile, wear. Thermal stability and fatigue behavior and reported that high strength and highest life cycle time were achieved [10].

\footnotetext{
*email:velmechresearch2021@gmail.com
} 
The integration of 2\% Nano clay particles on stitched glass fiber with epoxy resin composite contributed to an appreciable improvement in the mechanical and morphological behavior of composites that are adversely used in aerospace and marine applications [11]. The thermal, wear, viscoelastic and fatigue properties of a carboxyl-terminated butadiene acrylonitrile liquid rubber toughened silicon carbide and stitched E-glass fiber-reinforced epoxy composite have been produced and evaluated. Hand layup was used to create the composites, which were then post-cured at $120^{\circ} \mathrm{C}$. By incorporating micro rubber into epoxy resin, fatigue and viscoelastic characteristics were enhanced at the price of thermal stability and wear resistance [12].

P. Persico et al. [13] investigated the potential for cosmetic textile applications of melt compounded nylon 6 nanocomposites with various percentages of clay (Bentonite) /jajoba oil. The decomposition of oil from a nano clay composite fiber with a different morphology is part of the research. Sigma-Adrich et al. [14] developed and distributed a variety of nano-clay products and polymer composites. Many recent studies have focused on Bentonite with reinforced polymer matrix [15] for various properties. To date, no research has been performed on Bentonite reinforced Metal Matrix Composites (MMCs). As compared to pure polymer or traditional (micro-scale) composites, these nanocomposites exhibit significantly improved Physico-chemical properties, as demonstrated for the first time by Kojima and associates [16] for nylon clay nanocomposites. Moduli, strength and heat resistance are all improved. The presence of Bentonite to $5 \% \mathrm{wt} \%$ improved the tensile strength, tensile modulus, flexural strength and flexural modulus of tidy, according to Inceoglu and Yilmazer [17]. Taking this into account, the present investigation developed a glass fiber reinforced general polyester resin composite material with the addition of nano clay and the mechanical properties were evaluated using standard samples. In this study, the Hand layup technique is utilized to make Aluminium/Glass fiber reinforced polyester composites (A/GFRP), Bentonite/Glass fiber reinforced polyester composites (B/GFRP) and Aluminium and Bentonite/Glass fiber reinforced polyester composites (AB/GFRP).

\section{Materials and methods}

\subsection{Materials}

The matrix device ISO-4503 uses an unsaturated isophthalic polyester resin (IP) with a viscosity of 550-650 cps, an acid value of 14-20, a gel time of 20-30 min and a heat deflection temperature of $90^{\circ} \mathrm{C}$. As a catalyst, methyl ethyl ketone peroxide (MEKP) was employed, while cobalt naphthenate was used as an accelerator. Bentonite, a mined montmorillonite clay with a $p \mathrm{H}$ of 9-10.5 and a cation exchange capacity of $90 \mathrm{meq} / 100 \mathrm{~g}$ and aluminum powder are the inorganic clays utilized. Afterward, the clay is processed with dodecylamine, resulting in hydrophobic organo-modified clay (OMC). Since this inorganic clay is hydrophilic by nature, it cannot be used to make clay-polymer nanocomposites with organic polymers. Sodium activation was used to improve the swelling properties of Bentonite, as previously stated [17]. In the fabrication of hybrid Aluminium-polyester composites, E-glass fibers are utilized as reinforcement. This study's stitched E-glass fiber has a density of $2.54 \mathrm{~g} / \mathrm{cm}^{3}$ and a gram per square meter (GSM) of 400 . The actual weight of a bidirectional woven roving mat (WRM) is $610 \mathrm{~g} / \mathrm{m}^{2}$. The Sakthi fiberglass in Chennai provided all of the supplies.

\subsection{Preparation of specimen}

Hybrid AB/GFRPs with a laminate scale of $100 \mathrm{~mm} \times 50 \mathrm{~mm} \times 3 \mathrm{~mm}$ and 6 layers were prepared. Hand lay-up molding was very effective for producing parts of any size with a surface area of a few square feet and it is intended for small and medium volumes that require limited investment in molds and equipment. The epoxy base is a dense, translucent fluid. Manually mixing nanoparticles into it is difficult. A mechanical stirrer was employed to ensure the appropriate mixing of nano clay. At 1500 $\mathrm{rpm}$, mechanical stirring was performed for two h. Nano clay and Aluminum strength in various weight percentages were applied and stirred for $2 \mathrm{~h}$. Ultrasonication was used after mechanical stirring. It was done for $2 \mathrm{~h}$ in an ultrasonic bath. To create the proposed composite, three layers were laid out and cured fully at room temperature before being post-cured at $120^{\circ} \mathrm{C}$. The samples were fully cured by keeping 
them at room temperature for a day and then curing them at $120^{\circ} \mathrm{C}$ for $2 \mathrm{~h}$. Figure 1 illustrates the homogeneous dispersion of nano clay in comparison to clean epoxy samples. Similarly, B/GFRP and A/GFRP are prepared in the same manner in the polyester mix by hand layup technique.

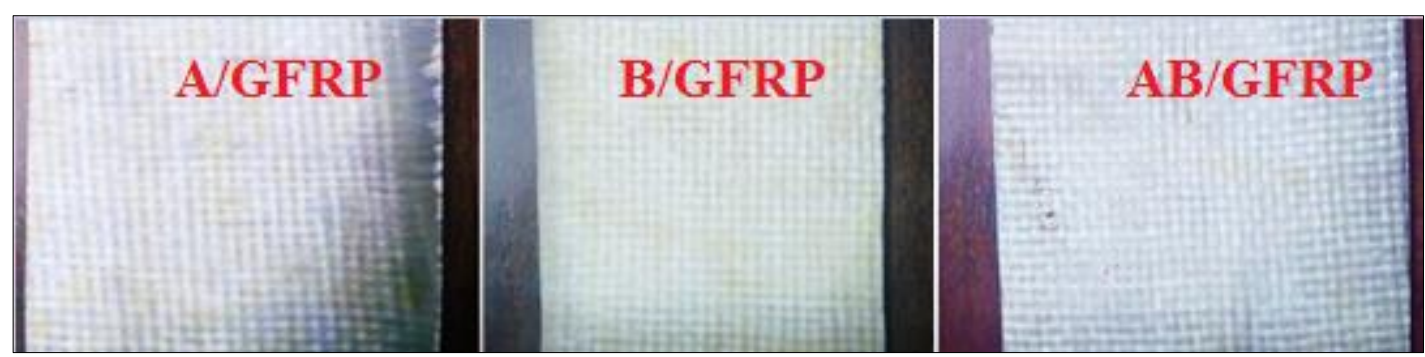

Figure 1. Fabrication sheet of aluminium glass fiber polyester laminate(A/GFRP), Bentonite glass fiber polyester laminate (B/GFRP) and combined aluminium \& Bentonite glass fiber polyester laminate (AB/GFRP)

Table 1. Composition of samples

\begin{tabular}{|c|c|c|}
\hline Description of samples & $\%$ of Matrix & $\%$ of Reinforcement \\
\hline A/GFRP & $50 \%$ Polyester & $50 \%$ Glass Fiber $+1 \%$ Aluminum Powder \\
\hline B/GFRP & $50 \%$ Polyester & $50 \%$ Glass Fiber $+1 \%$ Bentonite Powder \\
\hline AB/GFRP & $50 \%$ Polyester & $50 \%$ Glass Fiber $+0.5 \%$ Bentonite Powder $+0.5 \%$ Aluminium Powder \\
\hline
\end{tabular}

\subsection{Composite characterization Tensile test}

Tensile tests are used to determine the tensile modulus and breaking tensile strength of A/GFRP, $\mathrm{B} / \mathrm{GFRP}$ and AB/GFRP specimens as presented in Figure 4. Tensile properties were evaluated following ASTM D-638 standards utilizing universal testing equipment (FIE Pvt Ltd, India).

\section{Flexural test}

The three-point flexural test yields information on the material's modulus of elasticity in bending, flexural strain, flexural stress, and flexural stress-strain reaction. Flexural strength is a measure of the greatest stress encountered within a material at the point of rupture. The flexural test samples are cut conferring to ASTM D790 standard size specimen as presented in Figure 7. The flexural test was carried out at a test speed of $1 \% / \mathrm{min}$ with a loading of $0.1 \mathrm{MPa}$. The load is applied transversely at the middle of the laminate until the specimen bends and fractures. Both tensile test and flexural test done for five trials and the average values were taken into a conclusion.

\section{Hardness test}

The Barcol hardness test compares the depth of penetration of an indenter loaded on a material sample to the depth of penetration in reference material to determine material indentation hardness. Microhardness testing was done utilizing a METATECH India Ltd., Pune, India, Micro Hardness Tester, MUH-I. The hardness tester used in this experiment has a maximum load capacity of $1000 \mathrm{gms}$ with a dwell duration of $20 \mathrm{~s}$. Vickers' hardness value was measured using a $50 \mathrm{gms}$ pre-load. The application of load resulted in the formation of an imprint on the prepared specimen's surface. To get the average hardness value, the indent was noted on three separate random places on the specimen.

\subsection{Heat deflection test}

Humidity, immersion and exposure to boiling water all have the potential to produce markedly diverse material reactions. Equilibrium moisture content may be used to compare how much water various types of plastics absorb when exposed to moisture. Water absorption data is critical for understanding the polymeric materials' performance during processing, such as injection molding as 
shown in Figure 2, as well as in wet or humid conditions, to minimize early moisture-related failures ASTM D570.

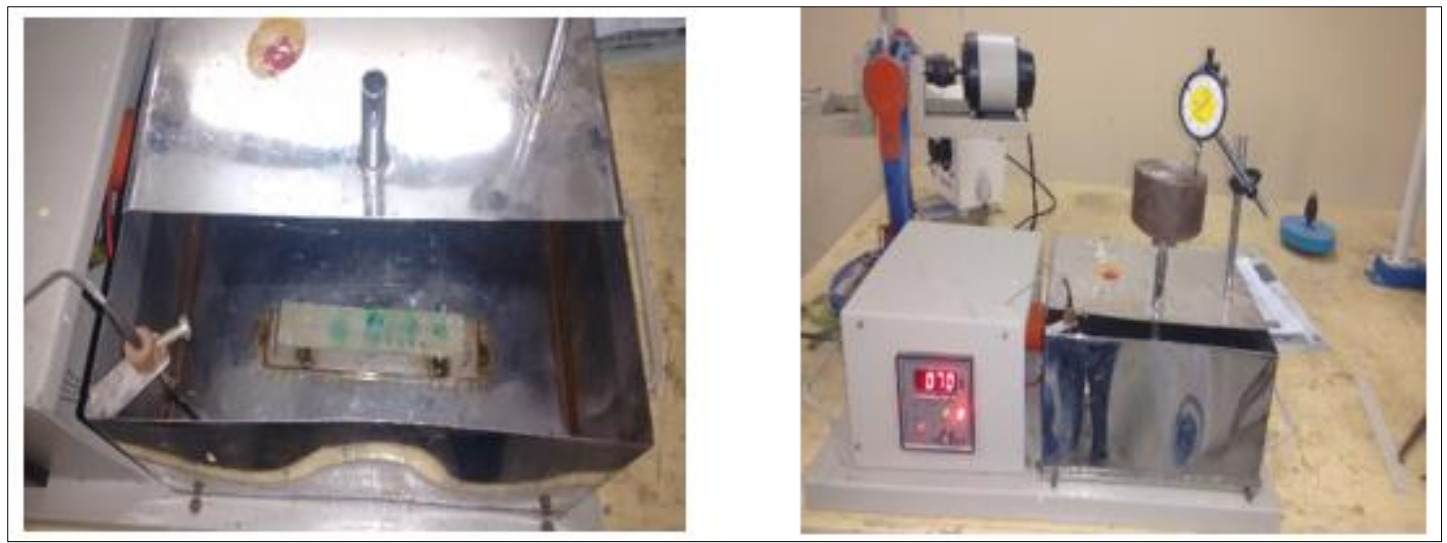

Figure 2. Heat defection test

\subsection{Micro structural analysis}

A scanning electron microscope (SEM) JEOL JSM 6610 LV, USA, was used to scan the surface morphology of tensile fracture surface samples. The samples were washed, thoroughly cleaned, air-dried and coated with gold to enhance conductivity before being examined using an SEM at $15 \mathrm{kV}$. SEM analysis was conducted at Anna University, India.

\section{Results and discussions}

\subsection{Tensile result}

The tensile strength of A/GFRP before temperature and after the temperature is $117 \mathrm{~N} / \mathrm{mm}^{2}$ and 141 $\mathrm{N} / \mathrm{mm}^{2}$. The improvement found in the B/GFRP of before temperature and after the temperature is 121 $\mathrm{N} / \mathrm{mm}^{2}$ and $194 \mathrm{~N} / \mathrm{mm}^{2}$ as depicted in Figure 3. The maximum value obtained of AB/GFRP of $160 \mathrm{~N} / \mathrm{mm}^{2}$ and $235 \mathrm{~N} / \mathrm{mm}^{2}$. It is determined by the fiber structure's hard personality. Researchers previously reported that crack pinning, bifurcation and other strengthening processes were seen in Aluminum Bentonite nanoparticle-filled composites to enhance the strength of clay-polymer nanocomposites [18].

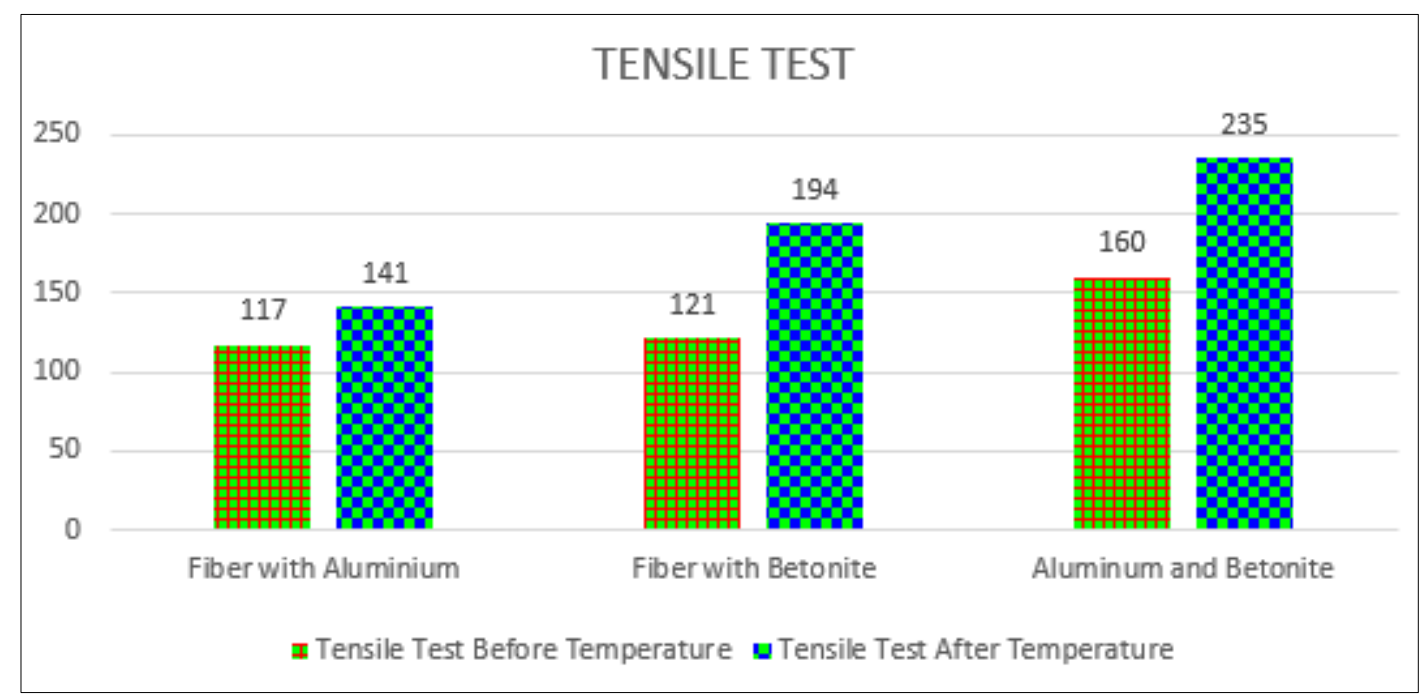

Figure 3. Tensile strengh of aluminium glass fiber polyester laminate, Bentonite glass fiber polyester laminate and combined aluminium \& Bentonite / glass fiber polyester laminate 


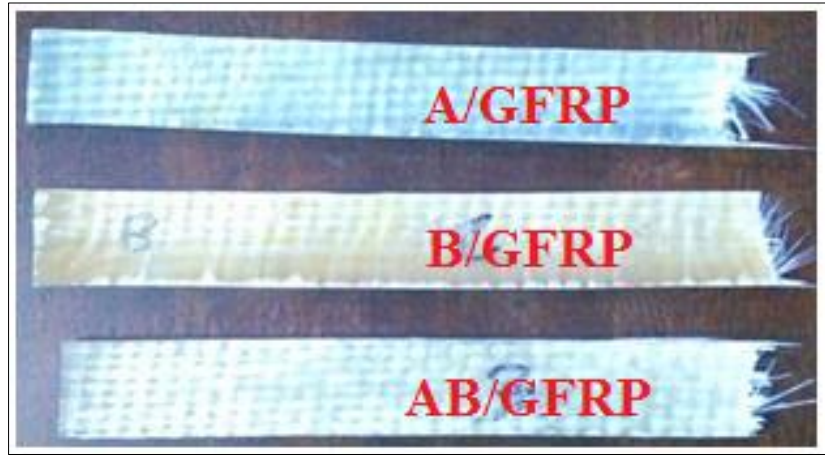

Figure 4. Tensile test laminate specimen
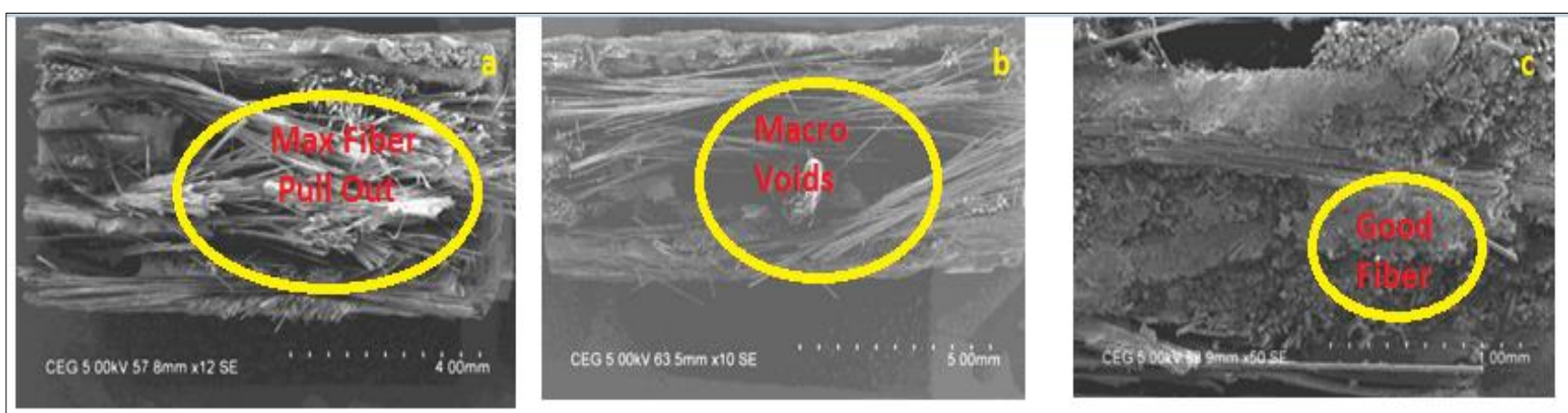

Figure 5. SEM picture of aluminium glass fiber polyester laminate, Bentonite glass fiber polyester laminate and combined aluminium \& Bentonite / glass fiber polyester laminate

\subsubsection{Tensile fracture surface morphology evaluation}

The tensile fracture surface of A/GFRP, B/GFRP, and AB/CFRP are shown in Figure 5. The fracture surface demonstrates that fiber pullout is the predominant failure mechanism. The fiber pullout demonstrates the matrix's poor interfacial interaction with the fiber. Additionally, energy loss was found during the frictional process mechanics [19]. At increasing clay concentrations, Figure 5a shows some micropores and fiber pullouts on the cracked surface, confirming the reduction in tensile characteristics of A/GFRP composites. Figure $5 b$ demonstrates the presence of micropores and fiber pullouts on the cracked surface at greater clay concentrations, which is not detrimental to A/GFRP. This demonstrates the deterioration of the tensile characteristics of B/GFRP composites. Additionally, fracture surface research indicates that intercalated and exfoliated clay platelets increase interfacial properties. Figure $5 \mathrm{c}$ demonstrates evidence of matrix deformation, fiber breakage rather than fiber drawing out, showing that there is no fiber aggregation and fibers are uniformly dispersed inside the matrix, imparting increased interfacial adhesion between them. Additionally, it demonstrates the enhancement of the tensile characteristics of the AB/GFRP composites [20].

\subsection{Flexural strength}

The flexural strength of A/GFRP before temperature and after the temperature is $153 \mathrm{~N} / \mathrm{mm}^{2}$ and $201.31 \mathrm{~N} / \mathrm{mm}^{2}$. The improvement found in the B/GFRP of before temperature and after the temperature is $169 \mathrm{~N} / \mathrm{mm}^{2}$ and $204.32 \mathrm{~N} / \mathrm{mm}^{2}$. The maximum value obtained of AB/GFRP of $180 \mathrm{~N} / \mathrm{mm}^{2}$ and 220.56 $\mathrm{N} / \mathrm{mm}^{2}$ as depicted in Figure 6. As a result of the fiber structure's hard nature. Researchers previously reported that crack pinning, bifurcation and improving the strength of clay-polymer nanocomposites, additional strengthening mechanisms were seen in Aluminium Bentonite nanoparticle-filled composites. [21]. 


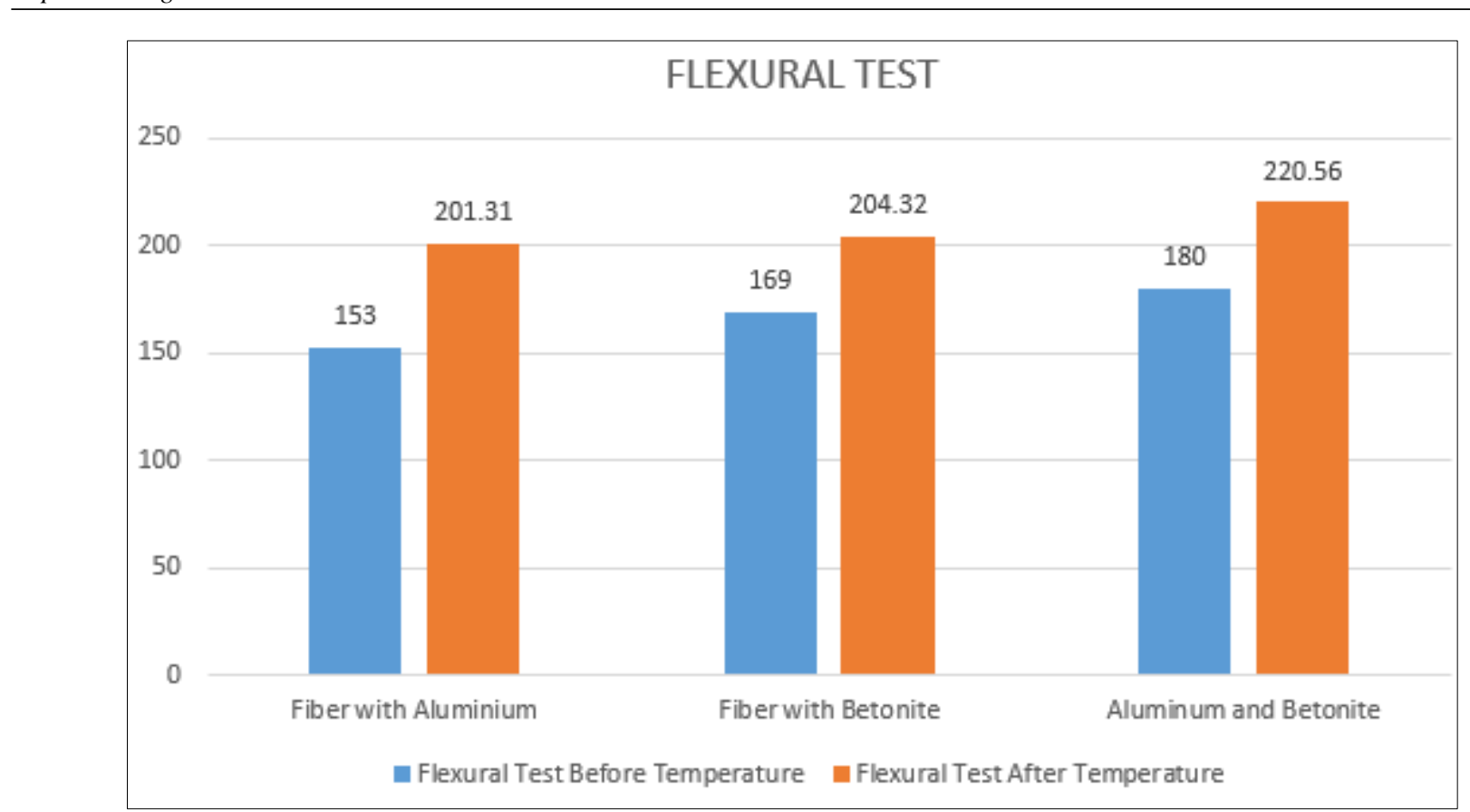

Figure 6. Flexural strength of aluminium glass fiber polyester laminate, Bentonite glass fiber polyester laminate and combined aluminium \& Bentonite / glass fiber polyester laminate

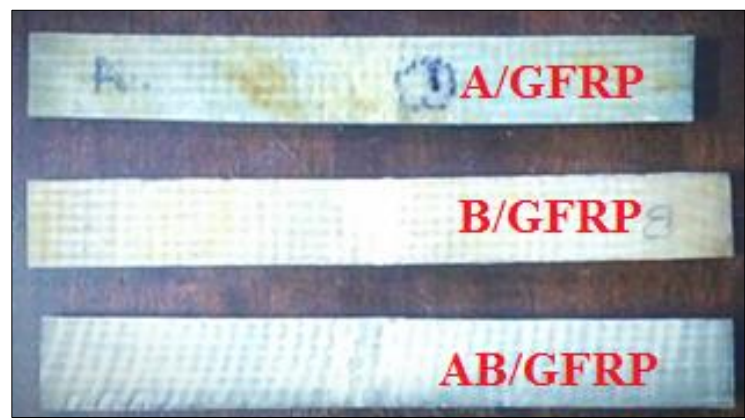

Figure 7. Flexural test laminate specimen

\subsection{Hardness}

The hardness of A/GFRP before temperature and after the temperature is $24.6 \mathrm{~N} / \mathrm{mm}^{2}$ and $27 \mathrm{~N} / \mathrm{mm}^{2}$. The improvement found in the B/GFRP of before temperature and after the temperature is $34 \mathrm{~N} / \mathrm{mm}^{2}$ and $38.2 \mathrm{~N} / \mathrm{mm}^{2}$. The maximum value obtained of AB/GFRPof $39 \mathrm{~N} / \mathrm{mm}^{2}$ and $41.2 \mathrm{~N} / \mathrm{mm}^{2}$ as depicted in Figure 8. It is determined by the fiber structure's rigid behavior. Fracture trapping, crack splitting, and other strengthening mechanisms have been found in Aluminum Bentonite nanoparticle-filled composites according to experts, to increase the strength of clay-polymer nanocomposites [22]. 


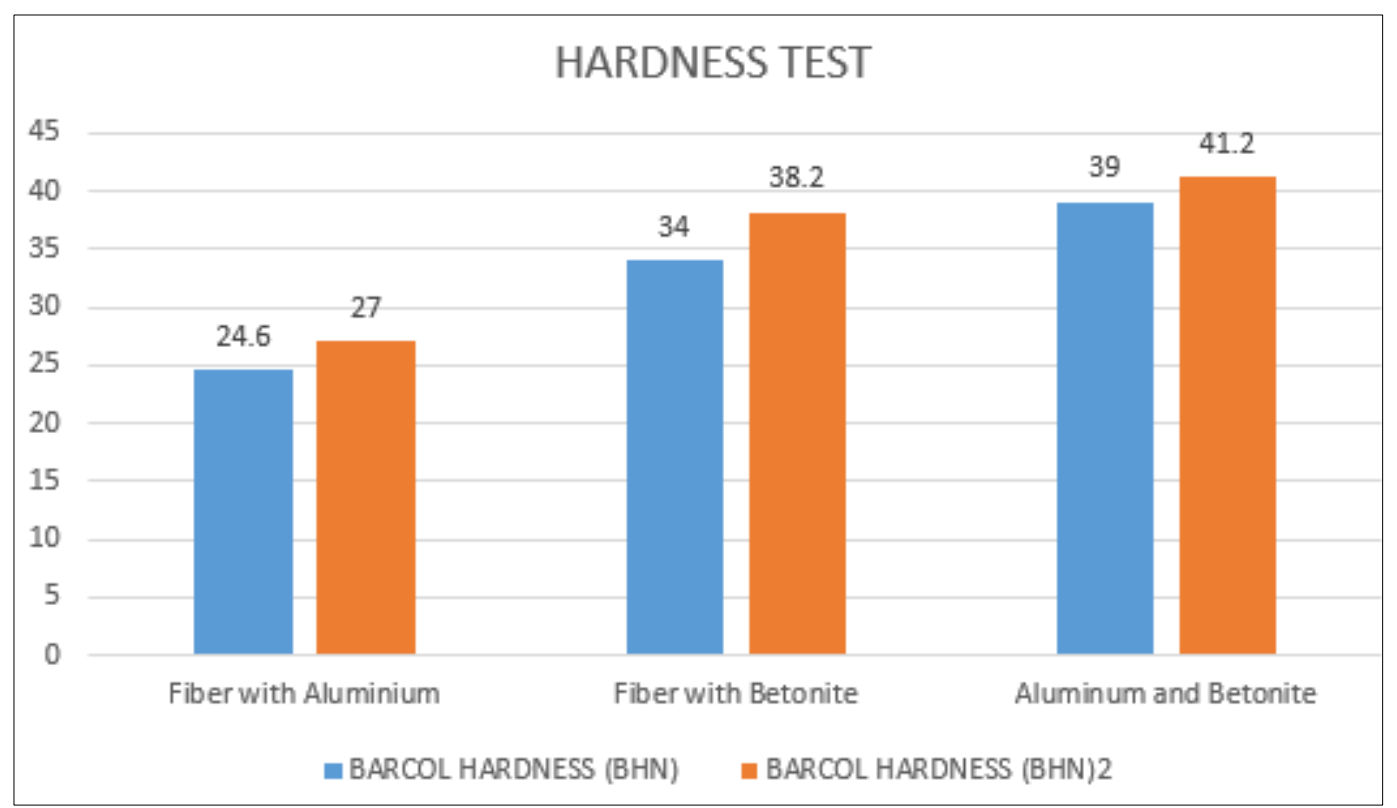

Figure 8. Hardness of aluminium glass fiber polyester laminate, Bentonite glass fiber polyester laminate and combined aluminium \& Bentonite / glass fiber polyester laminate

\section{Conclusions}

A/GFRP, B/GFRP and AB/GFRP are fabricated by the Hand layup method.

The experimental result shows that Bentonite clay and aluminum powder exist naturally in the polyester matrix of hybrid GFRP composites inducing the tensile strength, flexural strength and hardness have improved significantly.

The matrix deformation, rather than fiber extraction, indicates that there is no fiber aggregation and that the fibers are dispersed uniformly throughout the matrix, imparting improved interfacial adhesion between them. Additionally, it demonstrates the enhancement of the tensile characteristics of the AB/GFRP composites.

\section{References}

1. MATHIA,S., KLIEM JAN, H., QIAN, WAN., MARTIN, D., Characterization of clay-modified thermoset polymers under various environmental conditions for the use in high-voltage power pylons, Adv. Mech. Eng., 9(5), 2017, 1-16, https://doi.org/10.1177/1687814017698890

2.PALANIKUMAR, K., ASHOK GANDHI, R., BK RAGHUNATH, V JAYASEELAN, V., Role of Calcium Carbonate $\left(\mathrm{CaCO}_{3}\right)$ in improving wear resistance of Polypropylene (PP) components used in automobiles, Mater. Today: Proc., 16(2), 2019, 1363-1371,

https://doi.org/10.1016/j.matpr.2019.05.237.

3.KELLY, A., TYSON, W.R., High strength materials, John Wiley \& son, 1965, P. 578,

doi:10.1016/0016-0032(66)90363-2

4.ASHOK GANDHI, R., JAYASEELAN, V., RAGHUNATH, BK., PALANIKUMAR, K., RAMACHANDRAN, S., Nano Indendation Hardness Testing Of PP-CNT Composites, Mater. Today: Proc., 16, 2019, 1372-1377, https://doi.org/10.1016/j.matpr.2019.05.238.

5.ASHOK GANDHI, R., JAYASEELAN, V., PALANI KUMAR, K., RAGHUNATH, BK., KRISHNARAJ, S., Effect of Carbon Nano Tubes (CNT) on Hardness of Polypropylene Matrix, Advances in Materials and Metallurgy., 2019, 261-270,

https://doi.org/10.1007/978-981-13-1780-4_26. 
6.PRABHU, P., MOHAMED IQBAL, S., BALAJI, A., KARTHIKEYAN, B., Experimental investigation of mechanical and machining parameters of hybrid nanoclay glass fiber-reinforced polyester composites, Adv. Compos. Hybrid. Mater., 2, 2019, 93-101,

https://doi.org/10.1007/s42114-018-0065-y

7. JAYABALAKRISHNAN, D., SARAVANAN, K., RAVI, S., PRABHU, P., MARIDURAI., ARUN PRAKASH, VR., Fabrication and Characterization of Acrylonitrile Butadiene Rubber and Stitched EGlass Fiber Tailored Nano-Silica Epoxy Resin Composite, Silicon., 2020,

https://doi.org/10.1007/s12633-020-00612-0

8.RAVI, S., SARAVANAN, K., JAYABALAKRISHNAN, D., PRABHU, P., VIJAYANANTH, S., JAYASEELAN, V., MAYAKKANNAN, AV., Silane Grafted Nanosilica and Aramid Fibre-Reinforced Epoxy Composite: DMA, Fatigue and Dynamic Loading Behaviour, Silicon., 2021,

https://doi.org/10.1007/s12633-021-01060-0

9.KARTHIGAIRAJAN, M., NAGARAJAN, P.K., RAVIRAJA MALARVANNAN, R., RAMESH BAPU, BR., JAYABALAKRISHNAN, D., MARIDURAI, T., SHANMUGANATHAN., Effect of Silane-Treated Rice Husk Derived Biosilica on Visco-Elastic, Thermal Conductivity and Hydrophobicity Behavior of Epoxy Biocomposite Coating for Air-Duct Application, Silicon., 2020,

https://doi.org/10.1007/s12633-020-00772-z

10. ARUN PRAKASH, VR., JAYASEELAN, V., MOTHILAL, T., MANOJ KUMAR,S., MELVIN VICTOR,D., JAYABALAKRISHNAN, D., RAMESH, G., Effect of Silicon Coupling Grafted Ferric Oxide and E-Glass Fiber in Thermal Stability, Wear and Tensile Fatigue Behaviour of Epoxy Hybrid Composite, Silicon., 12,2020, 2533-2544, https://doi.org/10.1007/s12633-019-00347-7

11.VELMURUGAN, N., MANIMARAN, G., RAVI, S., JAYABALAKRISHNAN, D., Mechanical Property of Stitched Glass Fiber, Epoxy with Bentonite Clay Composite Using Hand Layup Method, Taga., J., 14, 2018, 162-176.

12.VELMURUGAN, N., MANIMARAN, G., RAVI, S., Effect of silanised reinforcements on thermal, wear, visco-elastic and fatigue behaviour of stitched E-glass fiber-reinforced epoxy hybrid composite, J. Rubber. Res., 24, 2021, 41-50, https://doi.org/10.1007/s42464-020-00070-8

13.PERSICO, P., CARFAGNA, C., MUSTO, P., Nanocomposite Fibers for Cosmetotextile Applicattions, Macromol. Symp., 234(1), 2006, 147- 155, https://doi.org/10.1002/masy.200650219

14. MAJEED, K., M. JAWAID, M., HASSAN, A., ABU BAKAR, A., ABDUL KHALIL, HPS., SALEMA, AA., INUWA, I., Potential materials for food packaging from nanoclay/natural fibers filled hybrid composites, Mater. Des. 46, 2013, 391-410. https://doi.org/10.1016/j.matdes.2012.10.044

15. KOJIMA, Y., USUKI, A., KAWASUMI, M., OKADA, A., FUKUSHIMA, Y., KARAUCHI, T., KAMIGAITO, O., Mechanical properties of nylon-6 clay hybrid, J. Mater. Res, 6, 1993, 1185-1189, https://doi.org/10.1557/JMR.1993.1185

16.INCEOGLU, AB., YILMAZER, U., Synthesis and mechanical properties of unsaturated polyester based nanocomposites, Polym. Eng. Sci., 43(3), 2003, 661-669.https://doi.org/10.1002/pen.10054

17.KORNMANN, X., BERGLUND, LA., STERTE, J., GIANNELIS, EP., Nanocomposites based on montmorillonite and unsaturated polyester, Polym.Eng. Sci., 38(8), 1998, 1351-1358.

https://doi.org/10.1002/pen.10305

18. GRAIN, MM., SHAMITIBA, BK., PETER, M., CHIZYUKA, GC., Response of natural sisal reinforced polyester composites to three-point and four-point bending, Procedia. Manuf, 7, 2017, 327332, https://doi.org/10.1016/j.promfg.2016.12.080

19.PARRE, A., KARTHIKEYAN, B., BALAJI, A., UDHAYASANKAR, R., Investigation of chemical, thermal and morphological properties of untreated and $\mathrm{NaOH}$ treated banana fiber, Mater. Today: Proc., 22(3), 2020, 347-352, https://doi.org/10.1016/j.matpr.2019.06.655

20.ELSAYED, A., ELBADRY, MOHAMED, S., ALY, H., HIROYUKI, H., Mechanical properties of natural jute fabric/ jute mat fiber reinforced polymer matrix hybrid composites. Adv. Mech. Eng., 2012, $1-12$, https://doi.org/10.1155/2012/354547 
21.PICKERING,KL., ARUANEFENDY, MG., Le, TM., A review of recent developments in natural fiber composites and their mechanical performance, Compos. - A: Appl. Sci. Manuf, 83, 2016, 98-112, https://doi.org/10.1016/j.compositesa.2015.08.038

22. MANWAR, H., YOUNG HUI, KO., YONG HO, C., Significant Enhancement of Mechanical and Thermal Properties of Thermoplastic Polyester Elastomer by Polymer Blending and Nanoinclusion, $\mathbf{J}$. Nanomater, 2016, 1-9, https://doi.org/10.1155/2016/8515103

$\overline{\text { Manuscript received: } 28.06 .2021}$ 